\title{
Habitat Selection in Dung Beetles (Family Scrabaeidae; Subfamily Scarabaeinae) in the Wasgomuwa National Park
}

\author{
Hewavithana D.K. ${ }^{1}$, Wijesinghe M.R. ${ }^{1}$, Dangalle C.D. ${ }^{1}$, Lekamge D. ${ }^{2}$ and De Silva C. \\ ${ }^{1}$ Department of Zoology, Faculty of Science, University of Colombo, Colombo 03, Sri Lanka \\ ${ }^{2}$ Sabaragamuwa University of Sri Lanka, Belihuloya, Sri Lanka \\ *mayuri@zoology.cmb.ac.lk
}

\begin{abstract}
A study was carried out to investigate habitat selection of dung beetles in terms of both habitat and dung types. The present study was considered necessary as information on the ecology of dung beetles in the dry zone of Sri Lanka is lacking. A total of 125 pitfall traps were set in five habitat types (dry-mixed evergreen forest, riverine forest, stream/river banks, scrubland and grassland) and using five types of mammalian dung (leopard, ungulate, elephant, bear and buffalo) as baits. The pitfall traps were laid in the morning and kept open for $24 \mathrm{hrs}$. A two-way ANOVA was conducted to discern significant differences between species richness and abundance of dung beetles across habitats and dung types.

A total of 455 individuals belonging to 22 species and 7 genera were recorded from the pitfall traps. This included one endemic species. Significant differences in species richness was apparent $(\mathrm{P}<0.05 ; \mathrm{F}=3.34)$ between the different habitat types with the highest number of species of dung beetles in the riverine habitat (20 species) and the lowest in stream/river bank habitats (8 species). No significant differences were recorded with respect to abundance across the habitat types. However there was a trend that, from among the five habitats, the stream/river banks showed highest abundance whilst the scrubland had the lowest abundance. Considering preferences of dung types, significant differences were apparent for both species richness $(\mathrm{P}<0.05 ; \mathrm{F}=4.09)$ and abundance $(\mathrm{P}<0.05 ; \mathrm{F}=0.02)$. The highest species richness was supported by leopard dung (19 species) whilst the lowest number of species (11 species in each) was observed in both bear and ungulate dung. Highest abundance of dung beetles was on bear dung whilst the lowest was on ungulate dung. Moreover some species were restricted only to a few habitats or dung types (Onthophagus cervus only in riverine habitat and Onthophagus quedentatus only in buffalo dung).
\end{abstract}

This study has for the first time revealed habitat and dung preferences among dung beetles in the dry zone Sri Lanka. Such information would be essential for the maintenance of a healthy population of dung beetles, which in turn would benefit natural ecosystems because of their invaluable ecological services.

Keywords: Habitat, Dung type, Selection, Preference 